\title{
WELL-BEING APPROACH OF A POWER SYSTEM CONTAINING RUN-OF THE-RIVER POWER PLANTS
}

\author{
Esmail Khalilzadeh¹, Mahmud Fotuhi-Firuzabad², Mehdi Ehsan³ \\ 1 Science and Research Branch, Islamic Azad University, Tehran, Iran, e-mail: esmailkhalilzadeh@yahoo.com \\ 2 Center of Excellence in Power System Management \& Control, Department of Electrical Engineering, Sharif \\ University of Technology, Tehran, Iran, e-mail: fotuhi@sharif.edu \\ 3 Department of Electrical Engineering, Sharif University of Technology, Tehran, Iran, e-mail: ehsan@sharif.edu
}

Received: 2017.07.28

Accepted: 2017.11.01

Published: 2017.12.05

\begin{abstract}
Renewable energies especially Run-Of the-River (ROR) power plants are increasingly used for the electricity generation in the power systems. The uncertain and intermittent nature of these plants arisen from variability of water flow, however, has led to some problems in their integration to power systems. Thus, the operating reserve requirement in a power system containing large ROR plants is a main challenge, which has to be addressed properly. In this way, this paper presents an analytical approach to determine the adequate spinning reserve based on the well-being approach during the system operation. The reliability model based on the components failures and uncertainty nature of water flow is introduced for ROR plants operation studies. This approach not only evaluates the interaction between these energies and conventional units, but also determines the contribution that ROR power plants can make in load carrying capability of a power generating system. Two reliability test systems, utilized from water flow data of Sheshpir River in Iran, are examined to demonstrate the effectiveness of the proposed model.
\end{abstract}

Keywords: uncertainty, water flow, operating reserve, run-of the-river (ROR) power plants, spinning reserve, well-being approach

\section{INTRODUCTION}

The necessity to reduce greenhouse gas emissions is driving the rapid growth of renewable energy sources in generation sector of power systems [1]. Among various renewable energy resources, the large-scale Run-Of the-River (ROR) power plants has become more mature. The 22 MW Mamquam and 25 MW Skookum ROR plants in Canada, 13 MW Yugur power plant in China, $42 \mathrm{MW}$ Brescia in Italy and 30 MW Yasouj plant in Iran, are only some examples of installed ROR generation units around the world. With cascading the single ROR plants, it is possible to deliver the generated power to the transmission system.

Variability and uncontrollability in renewable-based farms including wind, solar and ROR plants generations as well as being unable to accurately predict their productions are of the biggest obstacles for efficient use of these energies [2-5]. Moreover, conventional approaches become unable to accomplish power system studies in presence of renewable energies. These challengeable concerns are placed at the point of great consideration-demanding matters in the cases of wind and also PV farms integration in power systems [2-7]. However, to the authors' knowledge, in past works, the operation studies of a power system containing ROR units are not performed, and so it can be used from the similar researches performed on the wind and solar. For reserve determination of power system containing wind and farms, a vast number of studies have recently been presented in the published papers. The methods based on the deterministic 
approaches [7] are not able to use for renewablebased power systems. In contrast, a branch of probabilistic techniques have been proposed to assess the amount of capacity reserve in a more reliable way [8]. All these techniques, which are based on the PJM approach, can be introduced as efficient methods to evaluate short-term risks. References [9-10] emphasize that determining the optimal amount of operating reserve in presence of large-scale wind farms is a complex task. In [11], normal distribution is used for wind farm modelling and the SR value is obtained based on the concept of reliability cost-worth. In [12], scenario making method is applied for wind farm uncertainty modelling. References $[13,14]$ employ Monte Carlo chronological Simulation (MCS) method to evaluate the operating reserve of power systems with high penetration level of renewable energies.

This paper introduces an analytical model to evaluate the spinning reserve (SR) requirements of generating systems based on the well-being approach indices, in presence of ROR pants. The main idea of this paper is to establish a probabilistic multi-state model for ROR plants generations to be used in power system operating reserve studies. A suitable clustering approach, fuzzy c-means clustering method (FCM), is employed to find the most appropriate states associated with renewable-based units. The probability, departure rates and frequency of each state are obtained using the historical water flow data. The proposed method is applied to two various test systems, i.e., RBTS and IEEE-RTS. The rest of the paper is organized as follows. The multi-states analytical models associated with ROR plants are introduced. In the next section, is mainly devoted to the proposed spinning reserve assessment procedure based on the well-being approach indices. The other part, is comprised of three parts and involves in the implementation process of the proposed technique through two case studies. The conclusion is summarized in the final section.

\section{PROBABILISTIC ANALYTICAL MODEL OF ROR UNITS}

This section is thoroughly devoted to the proposed probabilistic models of ROR plants. In [15] the structure of a typical ROR power plant and its reliability model suitable for adequacy studies are introduced. In [15], the ROR power plant with n units, each with $\mathrm{m}$ penstocks, can be represented as a single unit with $m \times n$ penstocks. Here, the reliability model of a ROR plant considering both component failure rate and output power variability suitable for operation studies is presented. Due to short time period of operation studies, only one component failure is considered. Thus, only failures of power transformer or failure of an element associated to one of $m \times n$ branches are investigated. Failure of power transformer leads to zero production of ROR plant and failure of an element associated to one of $m \times n$ branches leads to the zero production of associated branch. Thus the reliability model of a ROR plant would be a shown in Figure 1.

In this model the generated power of a branch is considered to be $C$ and since the time horizon of the operation studies is short, it is impossible to repair or replace the failed components. As a consequence, the repair and replacement rates of these components are neglected in these studies. Utilizing the historical data of ROR production as the input data, the number and probability of some appropriate states associated with the ROR generation levels, can be determined using of the fuzzy C-means clustering method (FCM) [15]. Once the probabilistic model of ROR plant are obtained employing the FCM, the Markov model of a ROR plant consisted of $m \times n$ parallel branches can be extracted which is shown in Figure 2. In this figure the number of clusters associated to the uncertainty nature of water flow is considered to be $h$. The transition rates between different states can be determined from historical data of ROR generation power.

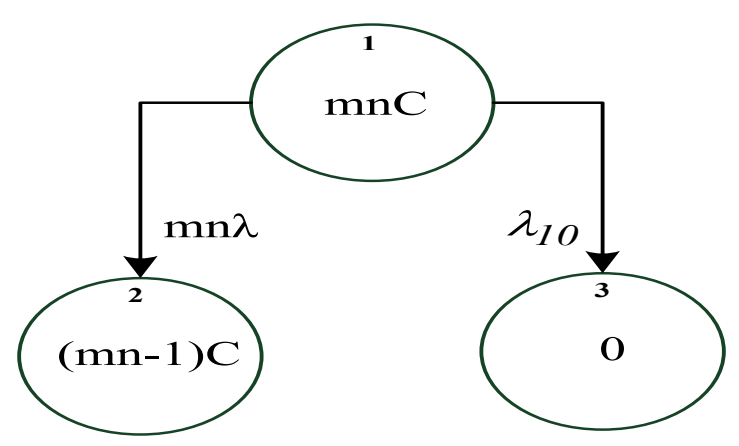

Fig. 1. The reliability model of a ROR plant (only component failure is considered) 


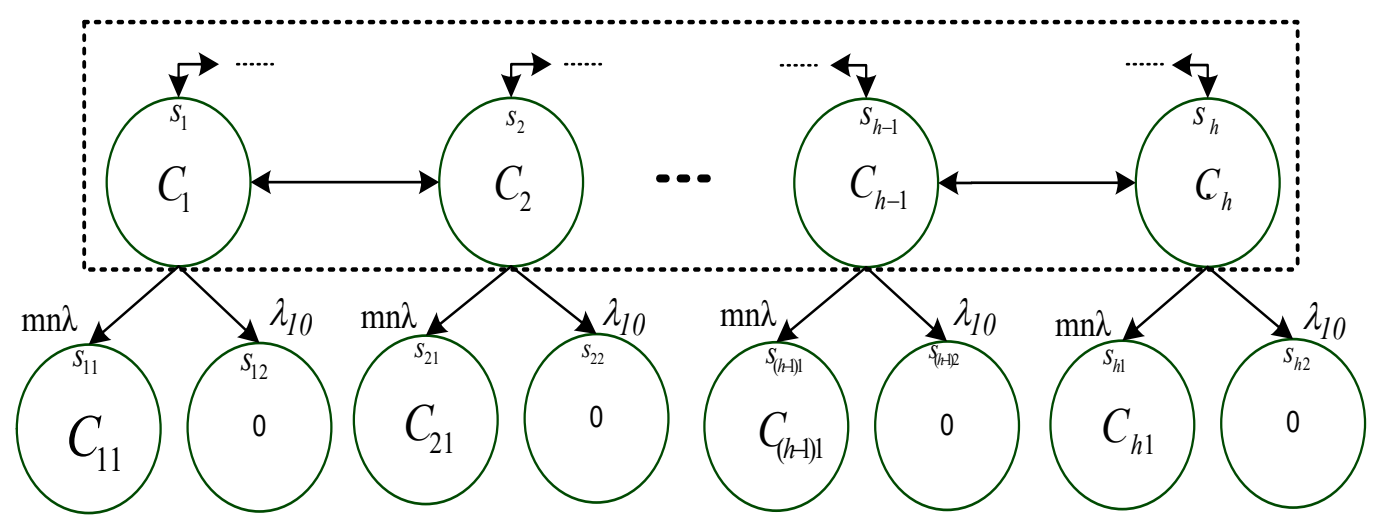

Fig. 2. The reliability model of a ROR plant

\section{SPINNING RESERVE ASSESSMENT PROCEDURE}

As mentioned earlier, the PJM method has shown its inevitable role in power system operating reserve evaluation procedure. To consider the intrinsic features of ROR plant generation in this method and to establish an effective method compatible with the nature of these energies, a new modified PJM method is presented in this section. It has been assumed that the reliability model of the conventional units is two-state model with up and down states. The probability of the down state in this model is obtained Eq. (1). where, $\lambda$ is the failure rate of the unit (occ./hr) and $T$ is the lead time.

$$
P(\text { down })=\lambda \times T
$$

The discussed models for ROR plant in the previous section are considered as the reliability models of these renewable-based units. Based on the PJM method, all units are supposed to be in the up states at time $t=0$ [16]. At the specified lead time, the probabilities of up and down states associated with all conventional units are calculated and the equivalent generation model is developed. The ROR plant multi-state model, however, can be involved in the PJM method by matrix multiplication technique as shown in (2). In this approach, the lead time $T$ is divided into several steps with $\Delta t$ duration.

$$
P(T)=P(0) \cdot[S T P M]^{(T / \Delta t)}
$$

Where, $\boldsymbol{P}(\boldsymbol{T}), \boldsymbol{P}(\boldsymbol{0})$ and $\boldsymbol{S T P M}$ respectively are the probability matrix of states at lead time $T$, probabilities of the states at the beginning of the studies which is extracted from the initial water flow data, and the stochastic transitional probability matrix. As the probabilities of various states are calculated, the multi-state models of ROR plants can be utilized to evaluate the Capacity Outage Probability Table (COPT) of these units for the predefined period of studies. The computed COPT is then convolved with the load model to deduce the well-being approach indices [17] including Healthy probability $(P(H))$, Marginal probability $(P(M))$, Unit Commitment Risk (UCR), SR, Peak Load Carrying Capability (PLCC) and Increase in PLCC (IPLCC) as defined below:

Healthy state: In this state, the generation capacity is more than the demand and the reserve is adequately high and is more than the capacity of the largest unit.

$$
\begin{aligned}
& P(H)=\sum_{i=1}^{k} P_{i}, \\
& \left(C_{i}>(\text { load }+ \text { capacity of } \text { larg est unit })\right)
\end{aligned}
$$

Marginal state: In this state, the generation capacity is more than the demand, but the reserve is not adequately high and is less than the capacity of the largest unit.

$$
\begin{aligned}
& P(M)=\sum_{i=1}^{k} P_{i}, \\
& \left(C_{i}>\text { load but } C_{i}<\right. \\
& <(\text { load }+ \text { capacity of larg est unit }))
\end{aligned}
$$

Risk state: In this state, the generation capacity is less than the demand.

$$
U C R=1-P(H)-P(M)
$$

Spinning Reserve: For defined load, the generation capacity is increased so that, the well-being approach indices is satisfied. The difference between generation capacity and demand is calculated as the spinning reserve. 
Peak load carrying capability: For specified generation capacity, the load is increased so that, the well-being approach indices is satisfied.

Increase in peak load carrying capability: For addition of a new generation unit, the previous load is increased so that, the well-being approach indices is satisfied. The difference between two loads is calculated as IPLCC.

\section{NUMERICAL RESULTS}

In this section, two well-known test systems, the RBTS and the IEEE-RTS, with addition of some ROR units are investigated. The reliability models of the new ROR units based on the proposed method are determined and the operation studies of these two test systems are performed and various power system well-being approach indices are calculated. Numerous analyses are then performed and impacts of lead time variation, peak load, scheduled capacity, penetration level of renewable resources and initial water flow on the system operation studies are investigated.

\section{THE RBTS CASE STUDY}

In this part, the RBTS is designated as a test system to examine operating reserve studies in presence of ROR plants. The original RBTS generating units data with $240 \mathrm{MW}$ installed capacity and their priority loading order are itemized in Table 1 [18].

For the original RBTS, the values of UCR index versus various lead times and peak loads are calculated and delineated in Figure 4. In this study, all units are committed which their equivalent scheduled capacity is $240 \mathrm{MW}$. As shown in this figure, any increment in peak load or lead time aggravates the $U C R$ index value. It is also deduced that the UCR index follows a discrete nature which is arisen from the individual gener-
Table 1. The RBTS units data and their priority loading order

\begin{tabular}{|c|c|c|c|c|}
\hline $\begin{array}{c}\text { Cap. } \\
\text { (MW) }\end{array}$ & Type & $\begin{array}{c}\text { No. of } \\
\text { units }\end{array}$ & $\begin{array}{c}\text { Priority } \\
\text { order }\end{array}$ & $\begin{array}{c}\text { Failure rate } \\
\text { (occ./yr) }\end{array}$ \\
\hline 40 & Hydro & 1 & 1 & 3 \\
\hline 20 & Hydro & 2 & $2-3$ & 2.4 \\
\hline 40 & Thermal & 2 & $4-5$ & 6 \\
\hline 20 & Thermal & 1 & 6 & 5 \\
\hline 10 & Thermal & 1 & 7 & 4 \\
\hline 20 & Hydro & 2 & $8-9$ & 2.4 \\
\hline 5 & Hydro & 2 & $10-11$ & 2 \\
\hline
\end{tabular}

ating unit capacities. To facilitate the conceptual understanding about the renewable-based units' impacts on the amount of SR requirements, the following cases are defined and put under investigation. The original RBTS is regarded as Case 1, in Cases 2, 3 and 4, respectively, a $30 \mathrm{MW}$ conventional unit with failure rate of $5 \mathrm{f} / \mathrm{yr}$, a 30 MW ROR unit with low initial water flow and a 30 MW ROR plant with high initial water flow are added to the original RBTS. As a notification, the added conventional unit in case 2 is scheduled as the last unit. In the other cases, the renewable based units are scheduled as the first units due to their free operating costs features.

The 30-MW ROR power plant with 5 single ROR units is considered to install on Sheshpir River in the Pars Province of Iran. Each single unit is composed of 4 penstock sets, that the capacity of each penstock with $2.2 \mathrm{~m}^{3} / \mathrm{s}$ water flow would be $1.5 \mathrm{MW}$. The reliability data of components of the power plant are given in [15]. The one-year water flow data associated to Sheshpir River in 2013 [15] is utilized for reliability model extraction of this ROR unit. The FCM technique results in 8 clusters, and the reliability model of the ROR unit, suitable for operation studies, is extracted which is shown in Figure 3.

The STPM of this model is as:

$$
S T P M=\left[\begin{array}{ll}
A & B \\
C & D
\end{array}\right]_{16 \times 16}
$$

$$
A=\left[\begin{array}{cccccccc}
1-0.043 \Delta t & 0.014 \Delta t & 0.005 \Delta t & 0.006 \Delta t & 0.001 \Delta t & 0.008 \Delta t & 0.004 \Delta t & 0.005 \Delta t \\
0.003 \Delta t & 1-0.007 \Delta t & 0.004 \Delta t & 0 & 0 & 0 & 0 & 0 \\
0.003 \Delta t & 0.014 \Delta t & 1-0.023 \Delta t & 0.006 \Delta t & 0 & 0 & 0 & 0 \\
0.006 \Delta t & 0 & 0.01 \Delta t & 1-0.028 \Delta t & 0.009 \Delta t & 0.003 \Delta t & 0 & 0 \\
0.003 \Delta t & 0 & 0 & 0.023 \Delta t & 1-0.043 \Delta t & 0.017 \Delta t & 0 & 0 \\
0.018 \Delta t & 0 & 0 & 0 & 0.011 \Delta t & 1-0.038 \Delta t & 0.005 \Delta t & 0.004 \Delta t \\
0.001 \Delta t & 0 & 0 & 0 & 0 & 0.009 \Delta t & 1-0.021 \Delta t & 0.011 \Delta t \\
0.006 \Delta t & 0 & 0 & 0 & 0 & 0.001 \Delta t & 0.014 \Delta t & 1-0.021 \Delta t]_{8 \times 8}
\end{array}\right.
$$




$$
B=\left[\begin{array}{ccccccc}
0 & 0 & 0 & 0 & 0 & 0 & 0 \\
0.008 \Delta t & 0 & 0 & 0 & 0 & 0 & 0 \\
0 & 0.008 \Delta t & 0 & 0 & 0 & 0 & 0 \\
0 & 0 & 0.008 \Delta t & 0 & 0 & 0 & 0 \\
0 & 0 & 0 & 0.008 \Delta t & 0 & 0 & 0 \\
0 & 0 & 0 & 0 & 0.008 \Delta t & 0 & 0 \\
0 & 0 & 0 & 0 & 0 & 0.008 \Delta t & 0 \\
0 & 0 & 0 & 0 & 0 & 0 & 0.008 \Delta t
\end{array}\right]_{8 \times 7}
$$

$$
\begin{aligned}
C & =[0]_{7 \times 8} \\
D & =[0]_{7 \times 7}
\end{aligned}
$$

The well-being approach indices for these four cases considering different peak loads at lead time of 4 hour are presented in Tables 2 to 5 . As expected and can be traced from these tables, addition of new generating units reduces the UCR and increases the healthy probability. The conventional unit, however, more efficiently im- proves the UCR index in compare to the renewable-based units.

Besides, the impacts of initial water flow on well-being approach indices are the other important thing which can be deduced from the attained results. Only when the water flow at the beginning of the studies is high, the ROR unit can play a key role in well-being approach improvement. The amount of required spinning reserve to satisfy the well-being approach indices $(\mathrm{UCR}<0.0001, \mathrm{P}(\mathrm{H})>0.985)$ versus different

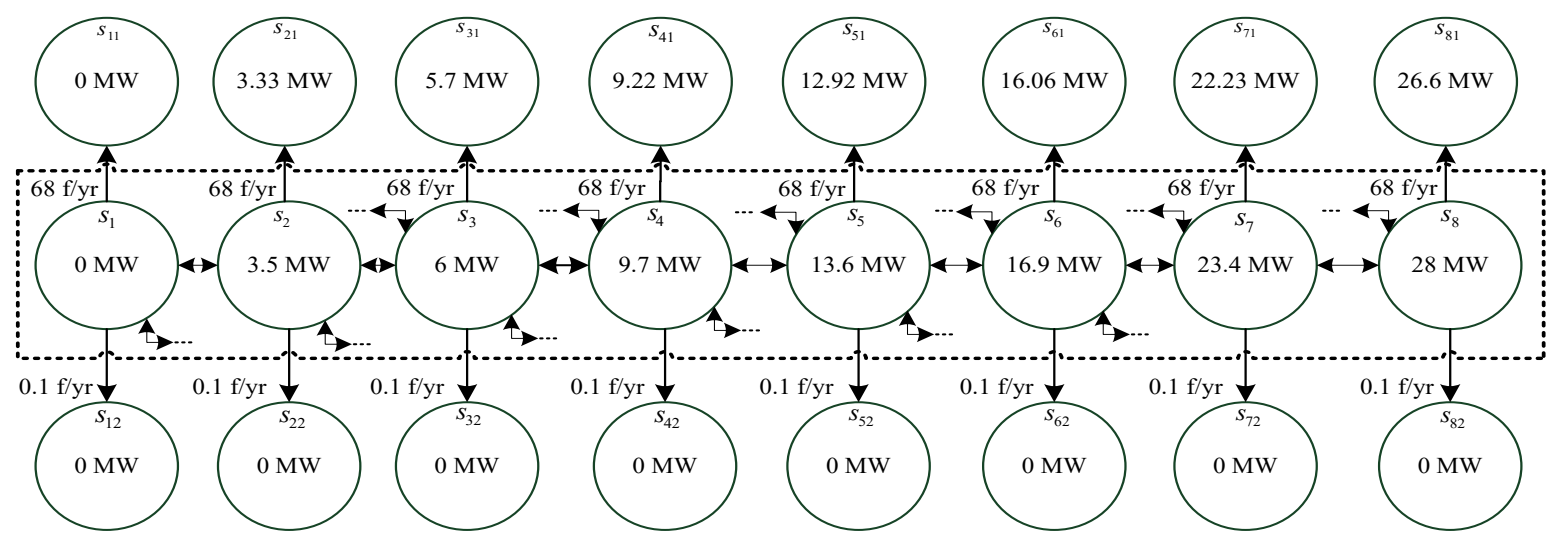

Fig. 3. The reliability model of 30 MW ROR plant

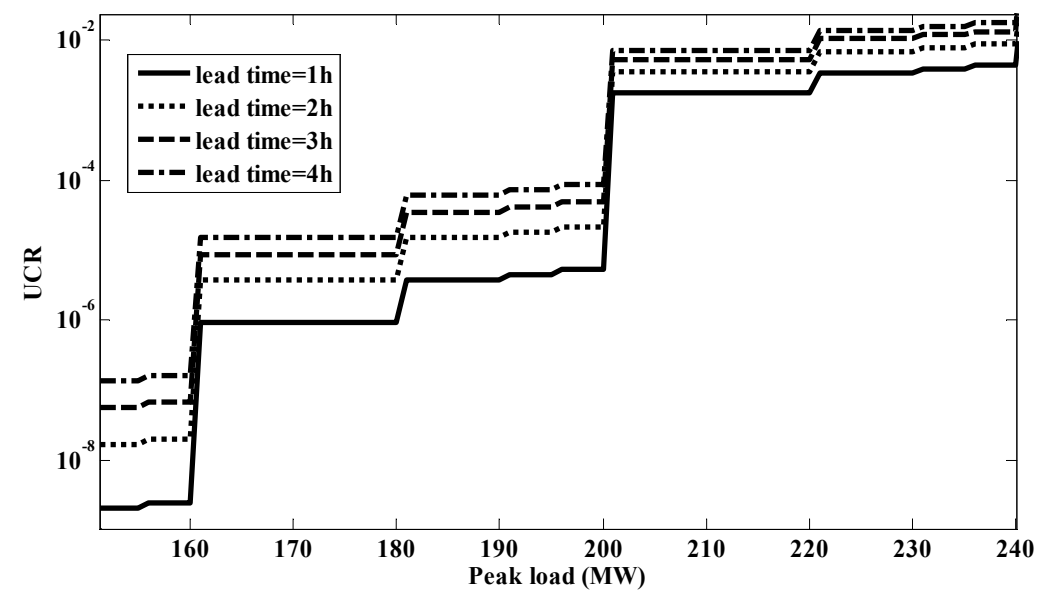

Fig. 4. The RBTS UCR index value versus different peak loads and lead times 
Table 2. Well-being states probabilities of Case I

\begin{tabular}{|c|c|c|c|}
\hline $\begin{array}{c}\text { Peak load } \\
\text { (MW) }\end{array}$ & $\begin{array}{c}\text { Healthy state } \\
\text { probability }\end{array}$ & $\begin{array}{c}\text { Marginal state } \\
\text { probability }\end{array}$ & $\begin{array}{c}\text { Risk state } \\
\text { probability }\end{array}$ \\
\hline 160 & 0.993149 & 0.006836 & $1.51 \mathrm{E}-05$ \\
\hline 170 & 0.993137 & 0.006848 & $1.52 \mathrm{E}-05$ \\
\hline 180 & 0.986562 & 0.013378 & $6.04 \mathrm{E}-05$ \\
\hline 190 & 0.984759 & 0.015168 & $7.28 \mathrm{E}-05$ \\
\hline 200 & 0 & 0.993149 & 0.006851 \\
\hline 210 & 0 & 0.993137 & 0.006863 \\
\hline 220 & 0 & 0.986562 & 0.013438 \\
\hline
\end{tabular}

Table 3. Well-being states probabilities of Case II

\begin{tabular}{|c|c|c|c|}
\hline $\begin{array}{c}\text { Peak load } \\
\text { (MW) }\end{array}$ & $\begin{array}{c}\text { Healthy state } \\
\text { probability }\end{array}$ & $\begin{array}{c}\text { Marginal state } \\
\text { probability }\end{array}$ & $\begin{array}{c}\text { Risk state } \\
\text { probability }\end{array}$ \\
\hline 160 & 0.999969 & $3.08 \mathrm{E}-05$ & $4.52 \mathrm{E}-08$ \\
\hline 170 & 0.999924 & $7.57 \mathrm{E}-05$ & $1.44 \mathrm{E}-07$ \\
\hline 180 & 0.999897 & 0.000103 & $2.75 \mathrm{E}-07$ \\
\hline 190 & 0.993129 & 0.006855 & $1.52 \mathrm{E}-05$ \\
\hline 200 & 0.990869 & 0.0091 & $3.08 \mathrm{E}-05$ \\
\hline 210 & 0.984309 & 0.015615 & $7.59 \mathrm{E}-05$ \\
\hline 220 & 0.982511 & 0.017386 & 0.000103 \\
\hline
\end{tabular}

Table 4. Well-being states probabilities of Case III

\begin{tabular}{|c|c|c|c|}
\hline $\begin{array}{c}\text { Peak load } \\
\text { (MW) }\end{array}$ & $\begin{array}{c}\text { Healthy state } \\
\text { probability }\end{array}$ & $\begin{array}{c}\text { Marginal state } \\
\text { probability }\end{array}$ & $\begin{array}{c}\text { Risk state } \\
\text { probability }\end{array}$ \\
\hline 160 & 0.998557 & 0.001443 & $7.92 \mathrm{E}-07$ \\
\hline 170 & 0.998399 & 0.001601 & $8.80 \mathrm{E}-07$ \\
\hline 180 & 0.996941 & 0.003056 & $3.31 \mathrm{E}-06$ \\
\hline 190 & 0.996351 & 0.003645 & $4.26 \mathrm{E}-06$ \\
\hline 200 & 0.156966 & 0.841591 & 0.001443 \\
\hline 210 & 0.065154 & 0.933244 & 0.001601 \\
\hline 220 & 0.030933 & 0.966007 & 0.003059 \\
\hline
\end{tabular}

Table 5. Well-being states probabilities of Case IV

\begin{tabular}{|c|c|c|c|}
\hline $\begin{array}{c}\text { Peak load } \\
\text { (MW) }\end{array}$ & $\begin{array}{c}\text { Healthy state } \\
\text { probability }\end{array}$ & $\begin{array}{c}\text { Marginal state } \\
\text { probability }\end{array}$ & $\begin{array}{c}\text { Risk state } \\
\text { probability }\end{array}$ \\
\hline 160 & 0.999961 & $3.86 \mathrm{E}-05$ & $2.09 \mathrm{E}-08$ \\
\hline 170 & 0.999957 & $4.33 \mathrm{E}-05$ & $2.35 \mathrm{E}-08$ \\
\hline 180 & 0.999908 & $9.23 \mathrm{E}-05$ & $9.30 \mathrm{E}-08$ \\
\hline 190 & 0.998239 & 0.00176 & $1.02 \mathrm{E}-06$ \\
\hline 200 & 0.976286 & 0.023675 & $3.87 \mathrm{E}-05$ \\
\hline 210 & 0.973573 & 0.026384 & $4.33 \mathrm{E}-05$ \\
\hline 220 & 0.966317 & 0.03359 & $9.23 \mathrm{E}-05$ \\
\hline 220 & 0.966317 & 0.03359 & $9.23 \mathrm{E}-05$ \\
\hline
\end{tabular}

Table 6. Spinning reserve values

\begin{tabular}{|c|c|c|c|c|}
\hline $\begin{array}{c}\text { Peak load } \\
(\mathrm{MW})\end{array}$ & Case 1 & Case 2 & Case 3 & Case 4 \\
\hline 160 & 50 & 50 & 50 & 50 \\
\hline 170 & 60 & 70 & 60 & 50 \\
\hline 180 & 55 & 60 & 50 & 45 \\
\hline 190 & - & 70 & 50 & 45 \\
\hline 200 & - & 70 & 45 & 40 \\
\hline
\end{tabular}

peak loads are calculated and shown in Table 6. In this study, system lead time is considered to be 4 hours. As can be traced in this table, for each system load level, the conventional units are added to the system based on their priority order. This procedure is continued till the well-being approach indices reach to a permissible level. In a specified load level, the spinning reserve is calculated as the difference between the scheduled conventional units and the peak load level. It can clearly be seen from this table that with addition of renewable-based units, the required spinning reserve values decrease. Thus the operation costs of the power system including renewable resources would be lower than that of traditional cases. It is also concluded from the table that the required spinning reserve for cases with ROR units with high water flow decreases the required spinning reserve significantly in compare with the low water flow conditions.

The PLCC associated with different cases satisfying well-being approach indices considering various lead times are evaluated and shown in Table 7 . The capability of the power system to supply loads increases by adding some renewablebased units to its generation sector. However, this improvement is affected by the initial conditions of the water flow and value of the lead time. Another valuable index, i.e. IPLCC, is calculated and analysed for different cases to more accurately study the impacts of renewable-based units in compare to conventional ones. In so doing, the peak load of the system can be increased as far as the well-being approach indices remains in permissible level. The attained results are illustrated in Table 8. As it is clear from the table, the addition of ROR plants with low initial water flow

Table 7. PLCC (MW) of different cases

\begin{tabular}{|c|c|c|c|c|}
\hline Lead time & Case 1 & Case 2 & Case 3 & Case 4 \\
\hline $1 \mathrm{~h}$ & 200 & 229.9 & 200.4 & 223.3 \\
\hline $4 \mathrm{~h}$ & 190 & 210 & 199.9 & 201 \\
\hline
\end{tabular}

Table 8. IPLCC (MW) of different cases

\begin{tabular}{|c|c|c|c|}
\hline Lead time & Case 2 & Case 3 & Case 4 \\
\hline $1 \mathrm{~h}$ & 29.9 & 0.4 & 23.3 \\
\hline $4 \mathrm{~h}$ & 20 & 9.9 & 11 \\
\hline
\end{tabular}


(Cases 3) cause no considerable improvement in load carrying capability of the power system in lead time 1 hour. However, it is not the case for high water flow conditions.

\section{THE IEEE-RTS CASE STUDY}

In this subsection, the IEEE-RTS is considered as a test system to investigate the impacts of different penetration levels of renewable resources on the system operation studies. The detailed data associated with this test system is presented in [19]. The UCR value for different ROR energies penetrations are evaluated and illustrated in Figures 5 and 6 . The lead time of this study is considered to be 4 hour. As it can be seen from these figures, although the addition of new renewable-based units improves the system risk level, this improvement at high penetration levels decreases.

Well-being approach indices associated to 4 cases including: the IEEE-RTS, IEEE-RTS and a $30 \mathrm{MW}$ conventional unit with failure rate of $5 \mathrm{f}$ / yr, IEEE-RTS and a $30 \mathrm{MW}$ ROR unit with low initial water flow, IEEE-RTS and a $30 \mathrm{MW}$ ROR plant with high initial water flow are calculated and presented in Tables 9 to 12. As can be seen in these tables, the well-being approach indices are improved when new unit is added to the system. However, the improvement associated to the conventional unit is more than the ROR units especially with low initial water flow. It is due to the uncertainty nature of these renewable units.

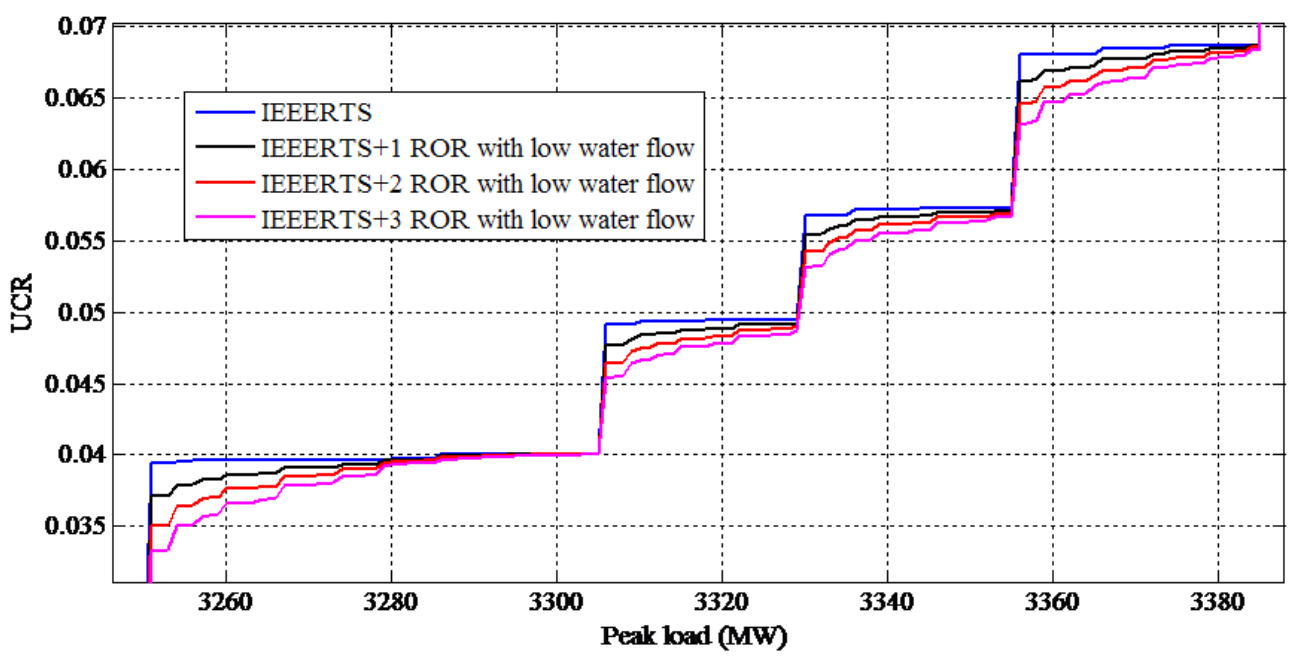

Fig. 5. The low water flow ROR energy impacts on UCR value

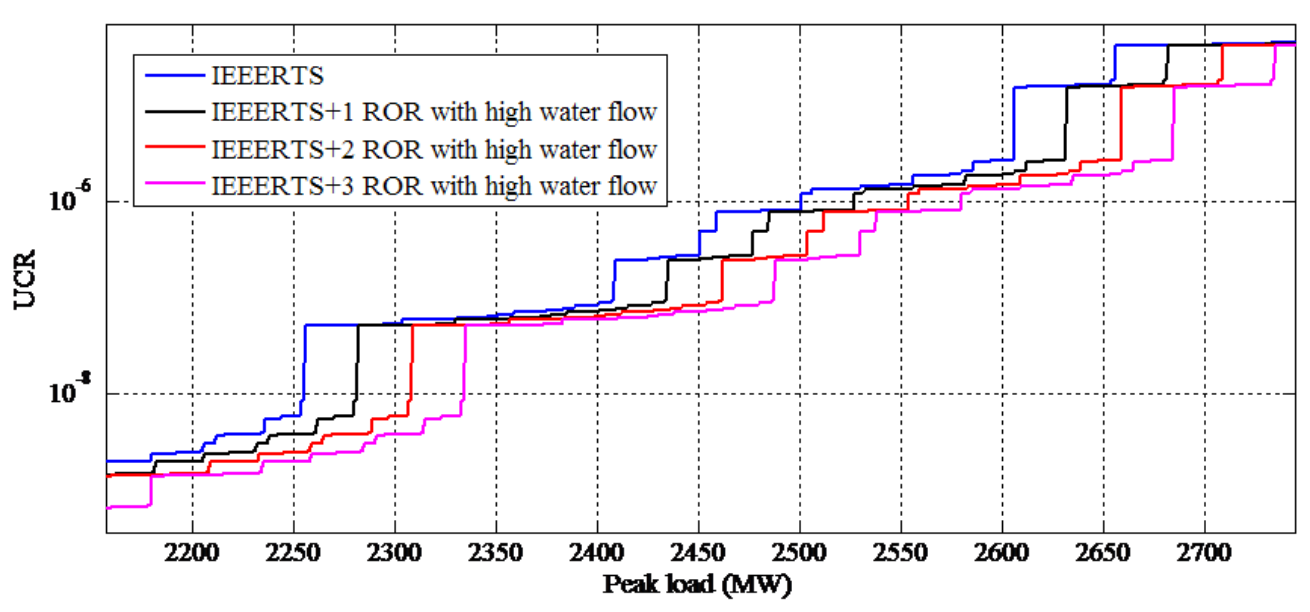

Fig. 6. The high water flow ROR energy impacts on UCR value 
Table 9. Well-being states probabilities of Case I

\begin{tabular}{|c|c|c|c|}
\hline $\begin{array}{c}\text { Peak load } \\
\text { (MW) }\end{array}$ & $\begin{array}{c}\text { Healthy state } \\
\text { probability }\end{array}$ & $\begin{array}{c}\text { Marginal state } \\
\text { probability }\end{array}$ & $\begin{array}{c}\text { Risk state } \\
\text { probability }\end{array}$ \\
\hline 2500 & 0.999644 & 0.000355 & $1.19 \mathrm{E}-06$ \\
\hline 2600 & 0.999083 & 0.000914 & $2.62 \mathrm{E}-06$ \\
\hline 2700 & 0.98889 & 0.011068 & $4.16 \mathrm{E}-05$ \\
\hline 2800 & 0.987565 & 0.012381 & $5.37 \mathrm{E}-05$ \\
\hline 2900 & 0.95992 & 0.039724 & 0.000356 \\
\hline 3000 & 0.893082 & 0.106001 & 0.000917 \\
\hline 3100 & 0 & 0.98889 & 0.01111 \\
\hline
\end{tabular}

Table 11. Well-being states probabilities of Case III

\begin{tabular}{|c|c|c|c|}
\hline $\begin{array}{c}\text { Peak load } \\
\text { (MW) }\end{array}$ & $\begin{array}{c}\text { Healthy state } \\
\text { probability }\end{array}$ & $\begin{array}{c}\text { Marginal state } \\
\text { probability }\end{array}$ & $\begin{array}{c}\text { Risk state } \\
\text { probability }\end{array}$ \\
\hline 2500 & 0.999653 & 0.000346 & $1.13 \mathrm{E}-06$ \\
\hline 2600 & 0.999103 & 0.000895 & $2.58 \mathrm{E}-06$ \\
\hline 2700 & 0.988901 & 0.011057 & $4.15 \mathrm{E}-05$ \\
\hline 2800 & 0.987631 & 0.012316 & $5.31 \mathrm{E}-05$ \\
\hline 2900 & 0.959948 & 0.039704 & 0.000347 \\
\hline 3000 & 0.895556 & 0.103547 & 0.000897 \\
\hline 3100 & 0 & 0.988901 & 0.011099 \\
\hline
\end{tabular}

Table 13. PLCC of different cases

\begin{tabular}{|c|c|c|c|c|}
\hline Lead time & Case 1 & Case 2 & Case 3 & Case 4 \\
\hline $1 \mathrm{~h}$ & 2954 & 2983 & 2960 & 2982 \\
\hline $4 \mathrm{~h}$ & 2941 & 2968 & 2949 & 2956 \\
\hline
\end{tabular}

In this stage the PLCC of different cases is determined and presented in Table 13. For PLCC determination the UCR is considered to be less than 0.0001 and the healthy state probability is considered to be more than 0.985 . Another valuable index, i.e. IPLCC, is determined and presented for different cases in Table 14, to more compare the impacts of conventional versus renewable units on the operation studies of the power system.

\section{CONCLUSIONS}

This paper introduces an analytical approach for operating studies and reserve determination of power systems with high penetration level of ROR
Table 10. Well-being states probabilities of Case II

\begin{tabular}{|c|c|c|c|}
\hline $\begin{array}{c}\text { Peak load } \\
\text { (MW) }\end{array}$ & $\begin{array}{c}\text { Healthy state } \\
\text { probability }\end{array}$ & $\begin{array}{c}\text { Marginal state } \\
\text { probability }\end{array}$ & $\begin{array}{c}\text { Risk state } \\
\text { probability }\end{array}$ \\
\hline 2500 & 0.999703 & $2.96 \mathrm{E}-04$ & $7.76 \mathrm{E}-07$ \\
\hline 2600 & 0.999396 & $6.02 \mathrm{E}-04$ & $1.87 \mathrm{E}-06$ \\
\hline 2700 & 0.988998 & 0.010961 & $4.08 \mathrm{E}-05$ \\
\hline 2800 & 0.988364 & 0.011589 & $4.69 \mathrm{E}-05$ \\
\hline 2900 & 0.960401 & 0.039302 & $2.97 \mathrm{E}-04$ \\
\hline 3000 & 0.931451 & 0.067946 & $6.04 \mathrm{E}-04$ \\
\hline 3100 & 0 & 0.988998 & 0.011002 \\
\hline
\end{tabular}

Table 12. Well-being states probabilities of Case IV

\begin{tabular}{|c|c|c|c|}
\hline $\begin{array}{c}\text { Peak load } \\
\text { (MW) }\end{array}$ & $\begin{array}{c}\text { Healthy state } \\
\text { probability }\end{array}$ & $\begin{array}{c}\text { Marginal state } \\
\text { probability }\end{array}$ & $\begin{array}{c}\text { Risk state } \\
\text { probability }\end{array}$ \\
\hline 2500 & 0.999702 & $2.97 \mathrm{E}-04$ & $7.85 \mathrm{E}-07$ \\
\hline 2600 & 0.99939 & $6.09 \mathrm{E}-04$ & $1.88 \mathrm{E}-06$ \\
\hline 2700 & 0.988995 & $1.10 \mathrm{E}-02$ & $4.08 \mathrm{E}-05$ \\
\hline 2800 & 0.98834 & $1.16 \mathrm{E}-02$ & $4.71 \mathrm{E}-05$ \\
\hline 2900 & 0.960391 & 0.039311 & 0.000298 \\
\hline 3000 & 0.930632 & 0.068758 & 0.00061 \\
\hline 3100 & 0 & 0.988995 & 0.011005 \\
\hline
\end{tabular}

Table 14. IPLCC of different cases

\begin{tabular}{|c|c|c|c|}
\hline Lead time & Case 2 & Case 3 & Case 4 \\
\hline $1 \mathrm{~h}$ & 29 & 6 & 28 \\
\hline $4 \mathrm{~h}$ & 27 & 8 & 15 \\
\hline
\end{tabular}

resources. For this purpose, a comprehensive reliability model of ROR units considering both associated components failure rates and uncertainty nature of the output power resulted from the variability in the water flow is developed and multistate model for these resources is obtained based on the FCM approach. Then, the PJM method is modified and these renewable resources models are used for determining well-being approach indices. Because of the uncertainty nature of ROR plant, it is recommended to determine the reserve value based on the well-being approach indices. For better representation of the proposed technique, two well-known reliability tests including RBTS and IEEE-RTS are considered and different number of $30 \mathrm{MW}$ Sheshpir ROR power plants is 
added to these systems. For analytical evaluation of the Sheshpir ROR power plant impacts on the power system operation studies, a 16-state reliability model based on the proposed approach is obtained. Several indices including healthy state probability, marginal state probability, unit commitment risk, spinning reserve, peak load carrying capability and increase in peak load carrying capability for these systems are determined based on the proposed technique. Furthermore, numerous sensitivity analyses are performed and it is concluded that the presence of renewable resources can improve the reliability of the power system in operation studies. It can be concluded from the numerical results, addition of ROR power plants to the power system results in the increase in the healthy state probability and also decrease in the system risk. It can be seen from the tables, with addition of the ROR power plants to the system, the peak load of the system can be increased so much that the reliability criteria is met. Improvement in the indices significantly increases as the initial water flow increases. This result highlights the importance of availability of high water flow in the performance and benefits of large ROR power plants. It is also concluded that due to the uncertainty nature of the water flow resulted in the de-rated states in the reliability model of these plants, the reliability improvement of renewable resources is less than conventional units with the same sizes.

\section{REFERENCES}

1. Zeng B., et al. Integrated planning for transition to low-carbon distribution system with renewable energy generation and demand response. IEEE Transactions on Power Systems, 29(3), 2014, 1153-1165.

2. Moeini-Aghtaie M., Abbaspour A. and FotuhiFiruzabad M. Incorporating large-scale distant wind farms in probabilistic transmission expansion planning-Part I: Theory and algorithm. IEEE Transactions on Power Systems, 27(3), 2012, 1585-1593.

3. Kamalinia S., Wu L. and Shahidehpour M. Stochastic midterm coordination of hydro and natural gas flexibilities for wind energy integration. IEEE Transactions on Sustainable Energy, 5(4), 2014, 1070-1079.
4. Zhao Q., et al. Evaluation of nodal reliability risk in a deregulated power system with photovoltaic power penetration. IET Generation, Transmission \& Distribution, , 8(3), 2014, 421-430.

5. Burke D. J. and O'Malley M. J. Maximizing firm wind connection to security constrained transmission networks. IEEE Transactions on Power Systems, 25(2), 2010, 749-759.

6. Ghaedi A., et al. Toward a comprehensive model of large-scale DFIG-based wind farms in adequacy assessment of power systems. IEEE Transactions on Sustainable Energy, 5(1), 2014, 55-63.

7. Teymour H. R., et al. Solar PV and battery storage integration using a new configuration of a threelevel NPC inverter with advanced control strategy. IEEE Transactions on Energy Conversion, 29(2), 2014, 354-365.

8. Lu S., et al. A model for optimizing spinning reserve requirement of power system under low-carbon economy. IEEE Transactions on Sustainable Energy, 5(4), 2014, 1048-1055.

9. Doherty R. and O'Malley M. A new approach to quantify reserve demand in systems with significant installed wind capacity. IEEE Transactions on Power Systems, 20(2), 2005, 587-595.

10. Siider L. Reserve margin planning in a windhydro-thermal power system. IEEE Transactions on Power Systems, 8(2), 1993, 564-571.

11. Ortega-Vazquez M. A. and Kirschen D. S. Estimating the spinning reserve requirements in systems with significant wind power generation penetration. IEEE Transactions on Power Systems, 24(1), 2009, 114-124.

12. Wang J., Shahidehpour M. and Li Z. Security-constrained unit commitment with volatile wind power generation. IEEE Transactions on Power Systems, 23(3), 2008, 1319-1327.

13. Leite Da Silva A. M., et al. Long-term probabilistic evaluation of operating reserve requirements with renewable sources. IEEE Transactions on Power Systems, 25(1), 2010, 106-116.

14. Billinton R., et al. Unit commitment risk analysis of wind integrated power systems. IEEE Transactions on Power Systems, 24(2), 2009, 930-939.

15. Khalilzadeh E., Fotuhi-Firuzabad M. and Ghaedi A. Reliability modeling of run-of the-river power plants in power system adequacy studies. IEEE Transactions on Sustainable Energy, 5(4), 2014, 1278-1286.

16. Billinton R. and Allan R. N. Reliability evaluation of engineering systems. plenum press, second edi- 
tion, London, 1992.

17. Billinton R. and Fotuhi-Firuzabad M. A basic framework for generating system operating health analysis. IEEE Transactions on Power Systems, 9(3), 1994, 1610-1617.

18. Billinton R., et al. A reliability test system for edu- cational purposes-basic data. Power Engineering Review, IEEE, 9(8), 1989, 67-68.

19. Reliability Test System Task Force of the Application of Probability Methods subcommittee. IEEE reliability test system, IEEE Transactions Power Applications System, 98(6), 1979, 2047-2054. 